\title{
Muscle blood flow in Duchenne type muscular dystrophy, limb-girdle dystrophy, polymyositis, and in normal controls ${ }^{1}$
}

\author{
OLAF B. PAULSON ${ }^{2}$, ANDREW G. ENGEL ${ }^{3}$, AND MANUEL R. GOMEZ \\ From the Department of Neurology and Neuromuscular Research Laboratory, Mayo Clinic \\ and Mayo Foundation, Rochester, Minnesota, U.S.A.
}

SYNOPSIS Muscle blood flow (MBF) was measured using the local ${ }^{133}$ Xenon injection method in patients with Duchenne type muscular dystrophy (six), limb-girdle dystrophy (four), polymyositis (seven), and in normal controls (11). Measurements were made at rest and during hyperaemia induced by ischaemic exercise and by histamine injection. Capillary diffusion capacity was measured with the ${ }^{51} \mathrm{Cr}$-EDTA method in three patients with Duchenne dystrophy and in six normal controls. Patients with Duchenne dystrophy had normal MBF during rest and during hyperaemia after exercise and significantly increased MBF after histamine injection. The capillary diffusion capacity was higher than normal, but not significantly. In limb-girdle dystrophy MBF was normal, while in polymyositis it was significantly decreased in all three circulatory states. The relevance of the findings to the proposed ischaemic aetiology of Duchenne dystrophy is considered.

The muscular dystrophies have been attributed classically to a primary degenerative process involving the muscle cell. However, during recent years several investigators have suggested that a circulatory abnormality might play an important role in the pathogenesis of the Duchenne-type dystrophy. The morphological basis for this hypothesis is as follows. Aortic ligation in the rat followed by treatment with vasoactive amines produces focal muscle fibre necrosis resembling the early stages of Duchenne dystrophy (Mendell et al., 1971; Mendell et al., 1972). Vascular embolization in the rabbit with $20-80 \mu \mathrm{m}$ dextran particles has a similar effect (Hathaway et al., 1970). If the vascular hypothesis were correct, then the blood flow in clinically affected muscles of patients with Duchenne dystrophy might be reduced in at least some physiological condition. To test this assumption, we measured the

\footnotetext{
1 This study was supported in part by Grants NBS 0663-07 and NS 6277 from the National Institutes of Health, Public Health Service.

2 During the conduct of this work Dr. Paulson was the recipient of a Fulbright-Hays Travelling Fellowship and a grant from Statens Laegevidenskabelige Forskningiråd, Denmark. Present address: Department of Psychochemistry, Rigshospitalet, Copenhagen, Denmark.

${ }^{3}$ Requests for reprints: Dr. Engel, Mayo Clinic, Rochester, Minnesota 55901, U.S.A.
}

muscle blood flow (MBF) in various neuromuscular diseases and in normal subjects using the inert gas ${ }^{133}$ Xenon. In addition, muscle capillary permeability was determined in some patients and controls.

\section{METHODS}

Seventeen patients and 11 normal subjects were studied. In each case informed consent was obtained from the patient, or, if a minor, from the parents. Six patients had Duchenne type muscular dystrophy, four had limb-girdle muscular dystrophy, and seven had polymyositis. The diagnosis in each case was based on the history, neurological examination, electromyography, and muscle biopsy. The serum creatine phosphokinase (CPK) level in patients with Duchenne dystrophy ranged from 2,530 to 6,976 units; in patients with limb-girdle dystrophy, from 244 to 1,536 units; in patients with polymyositis from 38 to 700 units (normal values: $<55$ units for females; < 75 units for males). In three of the six patients with Duchenne dystrophy there was evidence of $\mathrm{X}$-linked recessive inheritance (indicated by $*$ in Fig. 2). Asymptomatic mothers of these patients had significantly elevated serum CPK levels and the 5 and 7 year old boys were half-brothers with the same mother but different fathers. Of the seven 
TABLE 1

MUSCLE BLOOD FLOW DURING REST, AFTER ISCHAEMIC EXERCISE, AND AFTER LOCAL HISTAMINE INJECTION*

\begin{tabular}{|c|c|c|c|c|c|c|c|c|c|}
\hline & \multicolumn{3}{|c|}{ Resting blood flow } & \multicolumn{3}{|c|}{ Blood flow after ischaemic exercise } & \multicolumn{3}{|c|}{ Histamine induced hyperaemia } \\
\hline & $M e a n \pm S E$ & Range & $\begin{array}{l}\text { Patients } \\
\text { (no.) }\end{array}$ & $M e a n \pm S E$ & Range & $\begin{array}{l}\text { Patients } \\
\text { (no.) }\end{array}$ & $M e a n \pm S E$ & Range & $\begin{array}{l}\text { Patients } \\
\text { (no.) }\end{array}$ \\
\hline $\begin{array}{l}\text { Normal controls } \\
\text { Duchenne dystrophy } \\
\text { Limb girdle dystrophy } \\
\text { Polymyositis }\end{array}$ & $\begin{array}{l}2 \cdot 8 \pm 0.07 \\
2 \cdot 6 \pm 0.28 \\
2 \cdot 3 \pm 0.46 \\
1 \cdot 8 \pm 0.17 \dagger\end{array}$ & $\begin{array}{l}1 \cdot 5-3 \cdot 4 \\
1 \cdot 7-4 \cdot 0 \\
1 \cdot 1-3 \cdot 8 \\
1 \cdot 3-2 \cdot 8\end{array}$ & $\begin{array}{l}9 \\
4 \\
3 \\
4\end{array}$ & $\begin{array}{l}59 \pm 0 \cdot 72 \\
60 \pm 4 \cdot 0 \\
60 \pm 3 \cdot 8 \\
48 \pm 2 \cdot 9 \ddagger\end{array}$ & $\begin{array}{l}48-75 \\
56-80 \\
48-80 \\
20-75\end{array}$ & $\begin{array}{r}11 \\
3 \\
4 \\
7\end{array}$ & $\begin{array}{l}52 \pm 0 \cdot 88 \\
76 \pm 4 \cdot 1 \dagger \\
58 \pm 4 \cdot 5 \\
41 \pm 1 \cdot 8 \dagger\end{array}$ & $\begin{array}{l}40-70 \\
43-116 \\
40-78 \\
20-56\end{array}$ & $\begin{array}{r}11 \\
6 \\
4 \\
7\end{array}$ \\
\hline
\end{tabular}

* Results indicate $\mathrm{ml} . / 100 \mathrm{~g} / \mathrm{min}$. For each type of blood flow average of all measurements in given patient was used in calculating the group $\underset{7}{ }$ mean.

$\dagger$ Significant difference from controls at $P<0.001$.

$¥$ Significant difference from controls at $\mathbf{P}<0.01$.

patients with polymyositis three were being treated with prednisone at the time of the study (indicated by $\dagger$ in Fig. 2).

The blood flow in the patients was measured in slightly to moderately weak muscles. Similarly affected muscles were selected for the muscle biopsy and in several instances the blood flow measurements and the biopsies were taken from corresponding but opposite muscles of similar strength.

DETERMINATION OF MUSCLE BLOOD FLOW Muscle blood flow (MBF) was measured with ${ }^{133} \mathrm{Xe}$ dissolved in isotonic saline as described by Lassen and co-workers (1964). Before injection the muscle was carefully palpated to ensure deposition of the isotope into its substance; $0.05 \mathrm{ml}$ of a solution containing $150 \mu \mathrm{Ci}{ }^{133} \mathrm{Xe}$ was injected over 15 seconds with a 25 gauge needle into the muscle studied. In most cases this was the anterior tibial or the brachial biceps muscle. The needle was withdrawn 20 seconds after the injection. The clearance of the isotope was measured with a widely collimated sodium iodide crystal scintillation detector coupled to a ratemeter with a time constant of three seconds and equipped with a logarithmic recorder. The initial counting rate obtained was about $10^{5}$ counts per minute.

Three different types of MBF measurements were performed:

1. Measurements during rest After the ${ }^{133} \mathrm{Xe}$ injection the clearance curve was followed for 15 minutes. Because slight hyperaemia can be present during the first 5 to 10 minutes after injection, that part of the curve recorded during the last five minutes was used for the calculations.

2. Measurements during reactive hyperaemia after ischaemic exercise Five minutes after the injection of the isotope the circulation to the limb was occluded by a blood pressure cuff positioned around the upper thigh or arm and inflated to $250-300 \mathrm{mmHg}$. Next, the injected muscle was exercised as selectively as possible by voluntary flexion and extension until $\vec{\omega}$ complete exhaustion or intolerable pain appeared (60-100 movements). The cuff was then released and the ${ }^{133} \mathrm{Xe}$ clearance curve was followed for the next five minutes. MBF was calculated from the steepest. part of the curve.

3. Measurements of histamine-induced hyperaemin $30 \mu \mathrm{g}$ histamine and $150 \mu \mathrm{Ci}{ }^{133} \mathrm{Xe}$, dissolved inca volume of $0.05 \mathrm{ml}$, were injected and the clearan curve was followed for the next three minutes. MBF was calculated from the steepest part of the clearanese curve (Lindbjerg, 1965).

In all three types of measurement $\mathrm{MBF}$ was calculated from the clearance curves according to the formula:

$$
\mathrm{MBF}=0.70 \times 2.3 \times \mathrm{D} \mathrm{ml} / 100 \mathrm{~g} / \mathrm{min}
$$

where 0.70 is the muscle to blood partition coefficient for ${ }^{133} \mathrm{Xe} ; 2 \cdot 3$ the conversion factor from base 10 to natural logarithm; and D the slope of the logarithmically recorded clearance curve expressed in per cent of decade per minute.

DETERMINATION OF CAPILLARY DIFFUSION CAPACITY Capillary diffusion capacity was studied in three

TABLE 2

CAPILLARY DIFFUSION CAPACITY FOR ${ }^{51}$ Cr-EDTA*

\begin{tabular}{lcc}
\hline & Mean $\pm S E$ & Range \\
\hline Normal controls (6) & $3 \cdot 0 \pm 0 \cdot 09$ & $2 \cdot 3-4 \cdot 0$ \\
Duchenne dystrophy (3) & $3 \cdot 9 \pm 0 \cdot 28$ & $3 \cdot 2-4 \cdot 8$ \\
\hline * Values represent millilitres of interstitial fluid cleared from \\
100 g tissue per minute. In each case the diffusion capacity \\
was determined in the right and left anterior tibial muscle \\
and the average value thus obtained was used in calculating \\
the group mean.
\end{tabular}




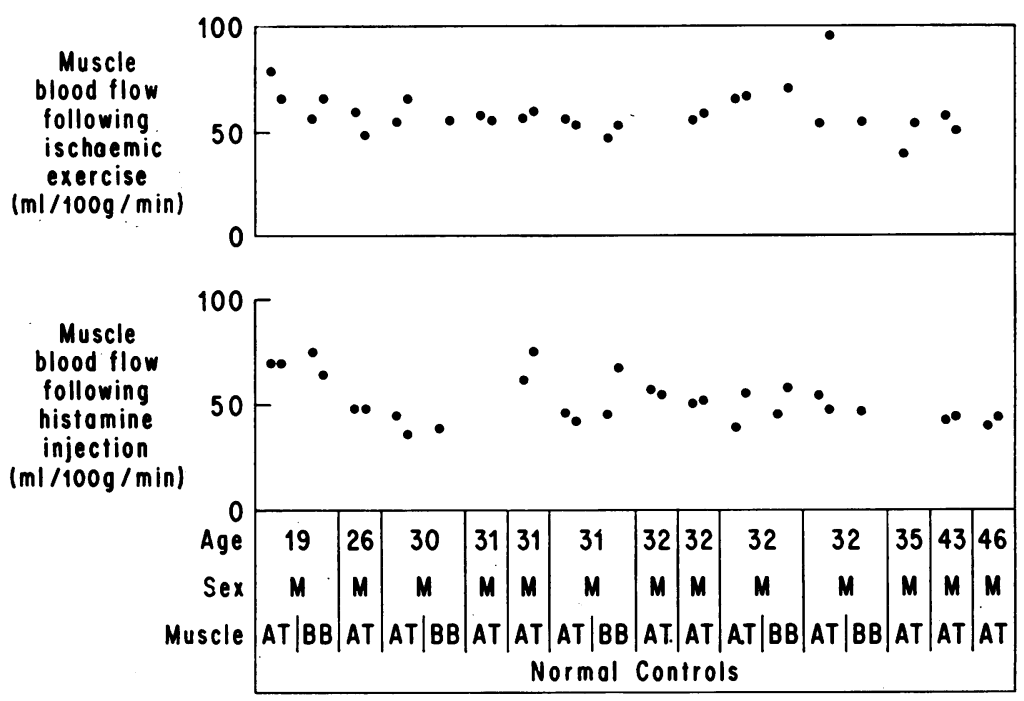

FIG. 1. Muscle blood flow after ischaemic exercise (upper panel) and histamine injection (lower panel) in 11 normal subjects. All measurements for each subject are indicated. For a given muscle, measurement on the right side precedes that on the left side. AT: anterior tibial; BB: brachial biceps.

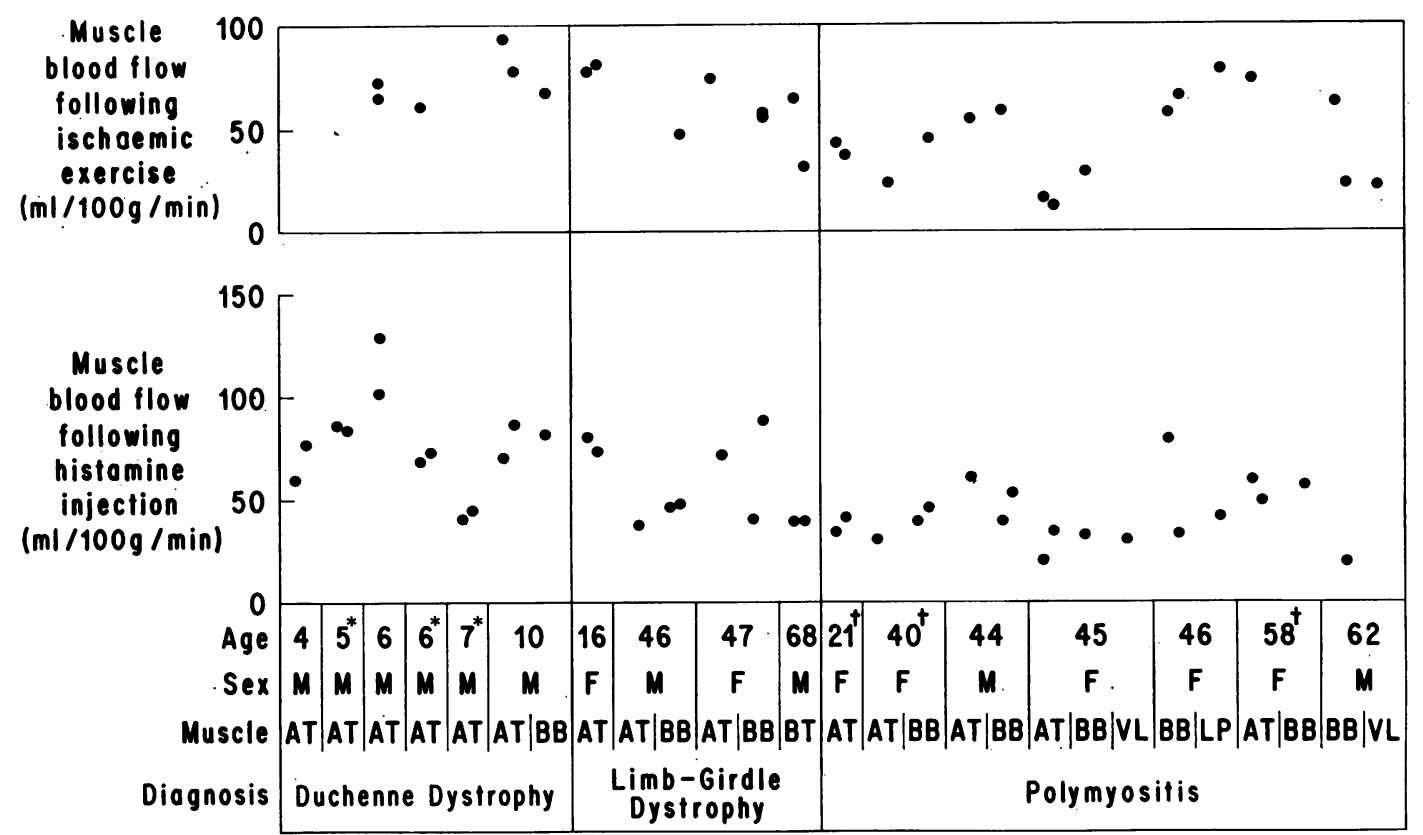

FIG. 2. Muscle blood flow in Duchenne dystrophy, limb-girdle dystrophy, and polymyositis after ischaemic exercise (upper panel) and histamine injection (lower panel). All measurements for each subject are indicated. For a given muscle, measurement on the right side precedes that on the left side. ${ }^{*}$ evidence for $X$-linked recessive inheritance; $\uparrow$ corticosteroid therapy. AT: anterior tibial; BB: brachial biceps; BT: brachial triceps; VL: lateral vastus; LP: long peroneal. 
patients with Duchenne dystrophy (those with evidence of X-linked recessive heredity) and in six normal controls. The ${ }^{51} \mathrm{Cr}$-EDTA- ${ }^{133} \mathrm{Xe}$ method was used in conjunction with histamine injection as described by Lassen and Trap-Jensen (1968) and by Trap-Jensen and co-workers (1970). A solution containing about $70 \mu \mathrm{Ci}^{133} \mathrm{Xe}, 30 \mu \mathrm{Ci}^{51} \mathrm{Cr}$-EDTA, and $30 \mu \mathrm{g}$ histamine was injected intramuscularly. To increase the counting rate, three scintillation detectors were used for recording the clearance curves. The combined pulses were registered by two ratemeters with three-second time constants and logarithmic recorders, and with pulse-height analysers set to count ${ }^{133} \mathrm{Xe}$ or ${ }^{51} \mathrm{Cr}$, respectively. With maximal counting rates of $10^{4}$ for the ${ }^{51} \mathrm{Cr}$ and $10^{5}$ for the ${ }^{133} \mathrm{Xe}$, less than $0.5 \%$ of the counts by the ${ }^{51} \mathrm{Cr}$ ratemeter were due to ${ }^{133} \mathrm{Xe}$, and about $1 \%$ of the counts by the ${ }^{133} \mathrm{Xe}$ ratemeter were due to the ${ }^{51} \mathrm{Cr}$. Capillary diffusion capacity was calculated according to the formulas of Lassen and TrapJensen (1968) and Trap-Jensen et al. (1970).

\section{RESULTS}

In patients with Duchenne dystrophy the mean MBF did not differ significantly from the normal control mean during rest or after ischaemic exercise. Histamine injection resulted in a significantly greater mean MBF in Duchenne dystrophy than in the controls (Figs 1 and 2, Table 1).

The mean capillary diffusion capacity determined in three patients with Duchenne dystrophy was greater than the corresponding value in the six normal controls but the two means were not significantly different $(P<0 \cdot 1)$ (Table 2$)$.

In patients with limb-girdle dystrophy the MBF was within normal limits during rest, after ischaemic exercise, and after histamine injection (Figs 1 and 2, Table 1).

The patients with polymyositis had significantly lower MBF during rest, after ischaemic exercise, and after histamine injection than did the normal controls under similar conditions (Figs 1 and 2, Table 1).

The variation in $\mathrm{MBF}$ values between different muscles of a given patient was small and only slightly more marked in patients with myopathies than in the controls (Figs 1 and 2).

For all cases, in the ischaemic exercise study the time interval from the release of the blood pressure cuff to maximal hyperaemia ranged from 10 to 45 seconds. The mean intervals for each group of cases (17-23 seconds) were not significantly different.

\section{DISCUSSION}

The local ${ }^{133} \mathrm{Xe}$ injection method provides an accurate determination of the local MBF. The isotope diffuses freely throughout the tissue and hence its washout curve is determined by the blood flow. Previous studies demonstrated a high degree of correlation between flow values obtained with ${ }^{133} \mathrm{Xe}$ method and values obtained by venous outflow measurements (Tönnesen and Sejersen, 1970).

The calculated blood flow in a given tissue depends on the product of the tissue to blood partition coefficient $(\lambda)$ and the slope of the ${ }^{133} \mathrm{Xe}$ clearance curve. For muscles $\lambda$ is relatively low $(0 \cdot 7)$, while for fatty tissue it is considerably higher. Partial fatty replacement of diseased muscle would increase $\lambda$ over 0.7 and therefore calculations using 0.7 as $\lambda$ would yield false low results (Lindbjerg et al., 1966). Thus, if fatt謧 replacement of dystrophic muscle had occurred the calculated MBF values would be lower than the true value. Therefore our measurements of normal or increased MBF in Duchenne dys trophy might even underestimate the true flow: However, the importance of this error is probably minor because only slightly or moderately affected muscles were studied and excessive fat replacement was not observed in the biopsy specimens.

Our findings may be contrasted with results obtained by other workers in Duchenne dystrophy. Emery and Schelling (1965), using venous occlusion plethysmography, obtained normal MBF values in the resting state. Demos et al. (1968), also using plethysmography, found a slightly higher than normal MBF at rest, a still higher MBF at low work loads, and relatively decreased values at high work loads. However, the plethysmographic method measures the total blood flow from the limb, including that from skin and subcutaneous tissues. Therefore, the total work performed by the entire limb of a non-weak person, and hence the total limb blood flow, will be inevitably higher than when a limb with reduced muscle bulk is exercised. This does not necessarily indicate that the blood flow per gram remaining muscle tissue is reduced. In our 
dystrophic patients in whom maximal hyperaemia was induced either by the maximum tolerated ischaemic exercise or by histamine, the maximum blood flow per gram muscle was not reduced below the normal level.

The present study demonstrates normal MBF at rest and after ischaemic exercise in Duchenne and limb-girdle muscular dystrophy and a significantly higher MBF after histamine injection in Duchenne dystrophy. The findings indicate that in the region permeated by the injected isotope an appreciable fraction of muscle could not have been ischaemic under the conditions of the study. However, the possibilities remain that (1) focal ischaemic lesions existed in muscle outside the injected regions; or that (2) coexisting focal ischaemia and hyperaemia at the microcirculatory level could have resulted in a normal or an increased average blood flow. The first assumption appears unlikely because the lesions in Duchenne dystrophy are essentially random in distribution and one might expect that at least some of the 22 injections in six patients after exercise or histamine injection would have coincided with an ischaemic site. If the second assumption were correct, the clearance curves in normal subjects and in Duchenne dystrophy should have had different configurations due to the coexistence of different clearance rates in the latter. This was not observed in the time period during which 80 to $90 \%$ of the injected isotope was cleared from muscle.

The significantly increased MBF after histamine injection in patients with Duchenne dystrophy can be related to recent morphometric findings by Jerusalem et al. (1974) of an increased capillary size and a normal number of capillaries per unit muscle fibre area in this disease.

Our observations on capillary diffusion capacity suggest that it also may be higher than normal in Duchenne dystrophy. However, with the limited number of patients the difference between the normal and dystrophic values did not reach statistical significance. If the capillary diffusion capacity were, in fact, increased in Duchenne dystrophy then this again would be consistent with the morphometric observations.

In seven patients with polymyositis the mean MBF was significantly decreased under all three conditions of measurements below the corresponding normal control levels. These findings lend support to the assumption that the microvascular bed is compromised in this disease. Morphological evidence for this has been previously reported in polymyositis (Shafiq et al., 1967; Gonzalez-Angulo et al., 1968) as well as in scleroderma and systemic lupus erythematosus (Norton et al., 1968).

\section{REFERENCES}

Demos, J., Treumann, F., and Schroeder, W. (1968). Anomalies de régulation de la micro-circulation musculaire chez les enfants atteints de dystrophie musculaire progressive par rapport à des enfants normaux du même âge. Revue Française d'Études Cliniques et Biologiques, 13, 467483.

Emery, A. E. H., and Schelling, J. L. (1965). Limb blood flow in patients and carriers of Duchenne muscular dystrophy. Acta Genetica et Statistica Medica, Basel, 15, 337-344.

González-Angulo, A., Fraga, A., and Mintz, G. (1968). Submicroscopic alterations in capillaries of skeletal muscles in polymyositis. American Journal of Medicine, 45, 873-879.

Hathaway, P. W., Engel, W. K., and Zellweger, H. (1970). Experimental myopathy after microarterial embolization. Comparison with childhood x-linked pseudohypertrophic muscular dystrophy. Archives of Neurology (Chic.), 22, 365-378.

Jerusalem, F., Engel, A. G., and Gomez, M. R. (1974). Duchenne dystrophy. I. Morphometric study of the muscle microvasculature. Brain (in press.)

Lassen, N. A., Lindbjerg, J., and Munck, O. (1964). Measurement of blood-flow through skeletal muscle by intramuscular injection of Xenon 133. Lancet, I, 686-689.

Lassen, N. A., and Trap-Jensen, J. (1968). Theoretical considerations on measurement of capillary diffusion capacity in skeletal muscle by the local clearance method. Scandinavian Journal of Clinical and Laboratory Investigation, 21, 108-115.

Lindbjerg, I. F. (1965). Measurement of muscle blood-flow with ${ }^{133}$ Xe after histamine injection as a diagnostic method in peripheral arterial disease. Scandinavian Journal of Clinical and Laboratory Investigation, 17, 371-380.

Lindbjerg, I. F., Andersen, A. M., Munck, O., and Jørgensen, M. (1966). The fat content of leg muscles and its influence on the ${ }^{133}$ Xenon clearance method of blood-flow measurement. Scandinavian Journal of Clinical and Laboratory Investigation, 18, 525-534.

Mendell, J. R., Engel, W. K., and Derrer, E. C. (1971). Duchenne muscular dystrophy: functional ischemia reproduces its characteristic lesions. Science, 172, 11431145.

Mendell, J. R., Engel, W. K., and Derrer, E. C. (1972). Increased plasma enzyme concentrations in rats with functional ischaemia of muscle provide a possible model of Duchenne muscular dystrophy. Nature, 239, 522-524.

Norton, W. L., Hurd, E. R., Lewis, D. C., and Ziff, M. (1968). Evidence of microvascular injury in scleroderma and systemic lupus erythematosus: quantitative study of the microvascular bed. Journal of Laboratory and Clinical Medicine, 71, 919-933. 
Shafiq, S. A., Milhorat, A. T., and Gorycki, M. A. (1967). An electron-microscope study of muscle degeneration and vascular changes in polymyositis. Journal of Pathology and Bacteriology, 94, 139-147.

Tönnesen, K. H., and Sejersen, P. (1970). Washout of ${ }^{133}$ Xenon after intramuscular injection and direct measurement of blood flow in skeletal muscle. Scandinavian Journal of $\overline{\mathbb{Q}}$ Clinical and Laboratory Investigation, 25, 71-81.

Trap-Jensen, J., Korsgaard, O., and Lassen, N. A. (1970). Capillary permeability to human skeletal muscle measured by local injection of ${ }^{51} \mathrm{Cr}$-EDTA and ${ }^{133} \mathrm{Xe}$. Scandinavian ${ }^{\circ}$ Journal of Clinical and Laboratory Investigation, 25, 93-99. T 